\title{
Investigating the Impact of Financial Inflows and Logistics Performance on Economic Growth Under the Shadow of Pandemic Crises: Empirical Analysis Using Dynamic Panel Estimation
}

\author{
Syed Abdul Rehman Khan ${ }^{1,2,3, *}$, Zhang Yu ${ }^{4}$, Laeeq Razzak Janjua ${ }^{5}$ and Adeel Shah ${ }^{6}$
}

\author{
${ }^{1}$ School of Management and Engineering, Xuzhou University of Technology, Xuzhou, China \\ ${ }^{2}$ Department of Business Administration, ILMA University, Karachi, Pakistan \\ ${ }^{3}$ Beijing Key Laboratory of Urban Spatial Information Engineering, Beijing, China \\ ${ }^{4}$ School of Economics and Management, Chang 'an University, Xi'an, China \\ ${ }^{5}$ Poznan University of Economics and Business, Poland \\ ${ }^{6}$ Institute of Business Management (IOBM), Karachi Pakistan \\ *Corresponding author.Email: khan.sar@xzit.edu.cn; sarehman_cscp@yahoo.com
}

\begin{abstract}
COVID-19 pandemic has severed the rate of economic growth almost in every country around the globe. The magnitude has been different due to the precondition of economic activities and severity for the speed of communicable disease spread. The developed, developing, and under developing countries by regulation and lockdowns can stop the spread. However, the measures slowdown to the economic activities. The world is still passing through a difficult situation, where many countries since March 2020 still face the 2nd and 3rd wave of the pandemic. The current research is an effort to bring forward insight into economic growth relationships, foreign direct investment, and logistic performance under the shadow of COVID-19 pandemic. For empirical testing, dynamic panel GMM (generalized method of moments) was used on data of forty-one countries. The findings show that higher FDI inflows and logistics performance spur international trade, while health expenditure and communicable diseases create pressure on economic growth. This study will help managers and policymakers to formulate effective policies for a global and local pandemic.
\end{abstract}

Keywords: COVID-19, Economic growth, Logistics performance, Financial inflows

\section{INTRODUCTION}

Sustainable economic progress has been the topic of interest for researchers and managers due to its practical implications and understanding the relationships between variables leading to increased economic progress [1]. The critical variable in the context of economic progress is infrastructure and investments [2]. Foreign direct investments (FDI) due to globalization and economic integration have contributed to developing new markets. Countries compete with each other to increase FDI and create a positive outlook for their respective economies. The FDI in the economy positively contributes to boosting economic activities by transferring capital investments technology, culture, and human resource skills [3]. The countries in pursuit of FDI inflows create an investment climate by regulating laws and introducing improved policies. Likewise, companies also improve and strengthen their production and logistics systems to increase competitive advantage. Many researchers have investigated the logistics function and economic growth [1, 4]. The researchers also presented their argument on logistic decoupling/coupling on economic growth. Similarly, some researchers also highlighted the importance of logistics as pivotal for industrializing society and its financial and systematic progress.

Logistics is key to link resources and markets, developing an integrated economy [5]. Logistics depends on numerous factors, including transportation, warehousing, energy consumption, infrastructure, information technology, and its impact on the environment. Due to competition, logistics is evolving. The subject now floods with digital technologies like blockchain, big data, digital twin, digital warehouse management, and other digital supply chain technologies. Companies' logistic capability contributes significantly to their respective country's economic growth by creating global chains and integrating different economies to deliver goods and services, thus earning foreign exchange and profits. Scholars have highlighted logistics contribution to lower inventories and reduce inventory-related losses [6], increasing FDI attractiveness and reducing lead times. Ref. [7], the transportation system in the logistic infrastructure is the main factor of its economic growth. Ref. [1] suggests that advanced and 
intelligent transport systems play vital roles in competing for FDI.

Economic growth, however, diminishes by pandemics due to the disruptions caused both regionally and internationally. Ref. [8] records a long list of regional and international outbreaks of diseases. The most disastrous in current times to result in a global pandemic is SARSCOVID 19. Meanwhile, during the research, the world faces the third wave of the worldwide pandemic. However, the phenomena will continue to devastate the economies of many countries during its path. The current research is also an effort in the same direction to understand pandemics' effects on the relationship between FDI, logistic performance, and economic growth by empirically testing panel data from different countries. The research will give insight to researchers and policymakers to understand the phenomena better and prepare governments and organizations to handle present and future scenarios.

\section{LITERATURE REVIEW}

Ref. [9, 7, 1] many studies in literature examine the relationship between FDI and economic growth. Similarly, for transportation [10-12]. The researchers have used different econometric techniques to test the relationship between economic growth and its other drivers. A few of the drivers identified that directly enhance economic growth are government infrastructure, energy consumption, transport, and logistics [13-14]. Ref. [2], many economists have investigated the improvement in infrastructure through capital and other means is an essential variable for calculating a neo-classical function of production [15]. Few researchers have also investigated the impact of logistics on attracting FDI and its role in increasing economic growth. However, transport infrastructure is a precondition to attract FDI and economic development [16]. The required infrastructure for transport consists of intermodal transportation mediums like motorways, roads, seaports, airports, and railways. The available infrastructure in a given country reduces the cost of business operations and reduces the lead time to distribute raw material and finished goods. The quality of transportation infrastructure attracts FDI and increases economic growth, confirmed by many published studies [1].

Ref. [17] testing the relationship between logistic infrastructure and economic growth between the years 1950 to 2000 for Mauritius. The test reveals the infrastructure development results to increase accessibility and cost reduction for domestic and foreign companies. Logistic has great economic value and has become an industry in any developing country, as confirmed by many research studies. A study by Lean et al. [18] analyzed the linkage between logistics and China's economic growth from 1980 to 2009 . The results reveal that both variables are positive and bi-directional in the longer run. Similar studies by Chu [19] suggest the same by highlight the importance of logistics which exceeds the boundaries of a business firm, to become a driver for economic growth in developing and developed countries. It confirms that logistics is essential for territorial economic development and growth. Information technology and systems are crucial for logistics performance.

They are combined with logistics and infrastructure, resulting in effective intermodal transport structures in a country that allows local and international businesses to reduce operational costs. The logistics cost reduces in storage, delivery, and transportation of material. In the global and competitive world, countries without proper logistics and infrastructure have failed to increase economic growth compared to their competitors. Logistics is most important for countries with significant geographical advantage for increased competitiveness. Business enterprises are continuously sourcing for countries to outsource their production to increase contribution margins. The FDI is pouring in countries providing professionals who can provide better services to global business at a lower cost [20]. The above theoretical evidence confirms that logistics is an essential factor for FDI, and both combine to result in economic growth.

\section{DATA SOURCE AND METHOD}

The research test linkages between economic growth, logistics, and FDI from the panel of 41 countries and from the year 2010 to 2020. Based on our research study, below is our first equation:

$$
\mathrm{T}_{i}=\partial_{0}+\beta_{1} \text { Econ }_{i}+\beta_{2} \text { Socio }_{i}+\beta_{3} \text { Cont }_{i}+\varepsilon_{i}
$$

Where $\mathrm{T}$ shows trade performance depends on economic growth and social well-being. The research requires us to use panel data of 41 countries to test our research objective, resulting in the panel data's estimation. Below is equation (2) to test trade performance.

$$
\begin{aligned}
& T_{i t}=\partial_{0}+\beta_{1 t} \text { Econ }_{i t}+\beta_{2 t} \text { Socio }_{i t}+\beta_{3 t} \text { Cont }_{i t} \\
& +v_{t}+\varepsilon_{i t}
\end{aligned}
$$

The test was conducted with Dynamic Panel GMM (generalized method of moments) estimators. The run test reduces the problem of heterogeneity and serial correlation. The endogeneity is tested for the independent variables using the Durbin-Wu-Hausman method concerning 2SLS The test is evident that some variables are endogenous. The endogenous and exogenous variables are mentioned in equation (3);

$$
\begin{aligned}
& T_{i t}=H E_{i t} Y_{1}+R E M_{i t} \beta_{1}+F D I_{i t} \beta_{2}+C D_{i t} \beta_{3}+ \\
& L_{i t} \beta_{4}+O D A_{i t} \beta_{5}+\mu_{1}+v_{i t}=Z_{i t} \delta+\mu_{i}+v_{i t}
\end{aligned}
$$

\section{RESULTS AND DISCUSSION}

The test conducts 41 countries' panel data from 2010 to 2020, stretching over 11 years. The section presents the test results; here, table (1) shows the descriptive statistics. $\mathrm{T}$ is trading, and the $\mathrm{CD}$ is a communicable disease called COVID-19. FDI is foreign direct investment, REM is remittance, ODA is official development assistance, HE is 
health expenditure, and L is logistic. In the variables, ODA

ODA are negative on minimum. is only a supporting variable. The FDI, remittance, and

Table 1. Descriptive statistics

\begin{tabular}{|l|c|c|c|c|c|}
\hline Variables & Obs & Mean & Std. Dev. & Min & Max \\
\hline T & 410 & 4.212447 & 0.408181 & 3.031221 & 5.349011 \\
\hline CD & 410 & 2.745602 & 1.045591 & 0.530628 & 4.269698 \\
\hline FDI & 410 & 0.907027 & 0.850251 & -2.12622 & 2.649412 \\
\hline REM & 410 & 1.097791 & 1.348111 & -2.62003 & 3.447838 \\
\hline ODA & 410 & -0.25118 & 1.48377 & -6.65571 & 3.062804 \\
\hline HE & 410 & 1.646997 & 0.354792 & 0.822078 & 2.338213 \\
\hline L & 410 & 1.000812 & 0.118532 & 0.703098 & 1.722767 \\
\hline
\end{tabular}

Table (2) is the correlational matrix that brings forward that economic growth $\mathrm{T}$ and its correlation during a pandemic are positive besides $\mathrm{CD}$ and $\mathrm{L}$. The communicable diseases negatively correlate with economic growth as countries went into lockdowns and smart lockdowns to stop and reduce the infectious rate. The FDI positively and in comparison to other variables strongly correlates with economic growth $\mathrm{T}$. Under the tested circumstances, remittance showed a very weak correlation with economic growth. Official development assistance increased during the period, as the correlation test suggests but reflects a weak correlation with economic growth. The health expenditure also reflects a weak correlation with economic trade; however, logistic performance reflects negatively correlated with economic trade. CD, however, shows to negatively correlates with all variables except for ODA (official development assistance). FDI positively correlates with all expected logistic performance; however, it reflects a strong correlation with HE (health expenditures). The REM (remittance) reflects a positive correlation higher with ODA and adverse to logistic performance. Also, REM reflects a very weak positive correlation with HE (health expenditure). ODA variable is negatively correlated with logistic performance; however, the test runs on the panel data reflect a weak correlation between ODA and HE. Lastly, HE reflects a weak positive correlation between logistic performances.

Table 2. Correlational matrix

\begin{tabular}{|c|r|r|r|r|r|r|r|}
\hline Variables & \multicolumn{1}{c|}{$\mathrm{T}$} & \multicolumn{1}{c|}{ CD } & \multicolumn{1}{c|}{ FDI } & REM & ODA & HE & L \\
\hline T & 1 & & & & & & \\
\hline CD & -0.2902 & 1 & & & & & \\
\hline FDI & 0.5054 & -0.3494 & 1 & & & & \\
\hline REM & 0.0334 & -0.2072 & 0.132 & 1 & & & \\
\hline ODA & 0.2177 & 0.2442 & 0.1122 & 0.3454 & 1 & & \\
\hline HE & 0.4004 & -0.3952 & 0.2763 & 0.0728 & 0.0613 & 1 & \\
\hline L & -0.0989 & -0.0946 & -0.1119 & -0.2414 & -0.3453 & 0.0519 & 1 \\
\hline
\end{tabular}

Table (3) reflects panel GMM and FGLS estimation regression. The findings show that communicable diseases and health expenditure are negatively correlated with trade. $1 \%$ increase in health expenditure and communicable diseases bring $-0.185 \%$ and $-0.154 \%$ reduction in trade activities. On the other hand, logistical performance and foreign direct investment inflows are positively associated with trade. The results show a $1 \%$ increase in logistical performance and foreign direct investment inflows spur international trade by $0.0129 \%$ and $0.003 \%$.

Below in figure (1) reflects the relation of trade and the COVID-19 pandemic. The link is inverse as the business demonstrates a decrease in pandemic effects due to lockdowns and regulations. The association is very consistent with researchers conducted by [21-22]. The predicted trends remain negative between trade and COVID-19.

Table 3. Regression analysis

\begin{tabular}{|cccc|}
\hline Variable & One step Difference GMM & One Step system GMM & FGLS \\
lag. Trade (\% of GDP) & 0.951 & 0.36 & - \\
\hline Communicable diseases (a proxy for covid-19). & $(0.063)^{* * *}$ & $(0.142)^{* * *}$ & -0.0581 \\
\hline & -0.006 & -0.154 & $(0.019)^{* * *}$ \\
\hline FDI (\% of GDP) & $(0.007)^{*}$ & 0.003 & -0.18 \\
& 0.016 & $(0.008)^{* *}$ & $(0.0203)^{* * *}$
\end{tabular}




\begin{tabular}{|cccc|}
\hline Remittances (\% of GDP) & 0.007 & 0.0896 & 0.045491 \\
& -0.004 & -0.052 & $(0.0134)^{* *}$ \\
\hline Official Development Assistance (\% of GDP) & -0.002 & -0.0054 & 0.06433 \\
& -0.008 & -0.013 & $(0.013)^{*}$ \\
\hline Health Expenditure ( \% of GDP) & -0.019 & -0.185 & -0.2704 \\
& $(0.026)^{* *}$ & $(0.108)^{*}$ & $(0.050)^{* *}$ \\
\hline Logistics Performance Index & 0.0247 & 0.0129 & 0.1063 \\
& $(0.064)^{*}$ & $(0.073)^{* *}$ & $(0.1461)^{* * *}$ \\
\hline Constant & 0.1759602 & 0.18963 & 3.9465 \\
\hline Number of instruments & $(0.260)^{* * *}$ & $(0.0596)^{* * *}$ & $(0.192)^{* * *}$ \\
AR(2) & 17 & 17 & - \\
\hline Hansen & 0.1896 & 0.3969 & 0.1374 \\
\hline
\end{tabular}

\section{CONCLUSION}

COVID-19 pandemic, a global phenomenon enveloped all of developed, developing, and under-developing countries. The economic meltdown was observed by all countries trying to recover from the lockdown's government to implement and regulate airborne diseases. The United Nations classified it as a global pandemic in March 2020. However, history is evident that diseases and pandemics have spread locally around the globe, disrupted economic growth, and indirectly put fatigue on the economy by health expenditures. For the same reason, the current study aims to provide an insight into the relationship between economic growth, foreign direct investment (FDI), and transportation performance in the shadow of the COVID19 pandemic. The questions that it aims to address are: (1) How do economies' growth react o FDI inflow in a country? (2) how to transport performance improves economic growth and lastly (3) during COVID-19 pandemic how these relationships will respond. To generalize the study, a dynamic panel data model of 41 countries empirically tested with the Generalized Method of Moments.

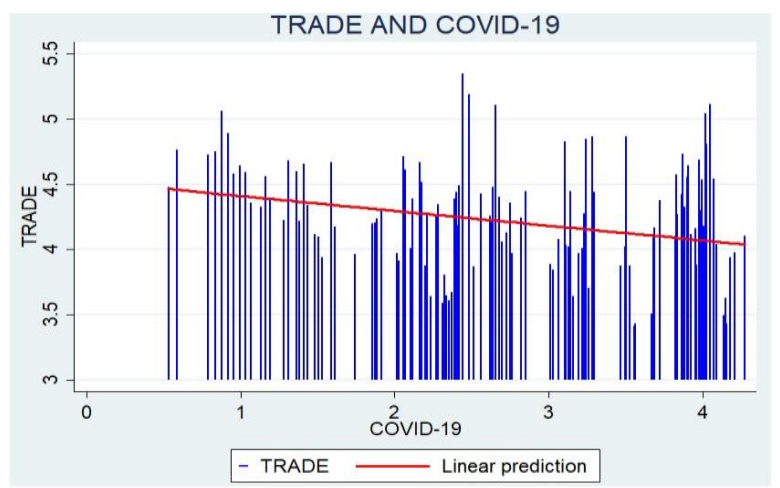

Figure 1. Relationship between trade and covid-19
The results drawn will contribute to the literature and enable researchers, managers, and policymakers to understand better how to mitigate future risks of pandemics by improving logistics systems and other economies to handle future pandemics.

Based on the study following policy implications are brought forward for managers and policymakers:

1. Pandemics are international and national phenomena and can irrupt at any point in time. Countries should equip health departments in their respective countries to monitor disease outbreaks with United Nations' help.

2. Health departments should keep track of the development in the area and possible remedies for prevention if it spreads in their country.

3. Economic managers of a country have the most crucial role in the pandemic. They will devise strategies to utilize and divert national resources to affected areas of the economy.

4. The economic managers should chalk out a plan to highlight sectors of the economy to implement lockdowns to stop communicable diseases. The priority economic sectors would better help governments to do planned lockdown without damaging the economy.

5. Foreign direct investments (FDI) decline during a pandemic, but better logistic systems and economic management will attract foreign investors to realize their profits.

6. The economic managers should initiate financial products during the pandemic to attract foreign investments.

7. Logistics systems are one of the essential factors contributing to economic growth. Countries without a proper logistics network are unable to attract foreign investments.

8. Countries should invest in logistics systems, especially mediums, to make intermodal transport efficient: highways, roads, seaports, airports, and rails.

9. The governments should invest in information communication technology (ICT) to direct the economy via e-commerce and make logistic systems more efficient. 
10. ICT has proven to be the most critical technology to assist millions worldwide during lockdowns. People can trade and buy consumable goods through e-commerce. Government should enable functional portals for necessities to assist their nationals and foreigners.

11. The most important of all is the justice and police systems in a country. It will enable FDI even in a pandemic as investors would feel secure.

12. Government should invest in health infrastructure to assist the patients during the pandemic.

13. Cities should be planned to lockdowns in a particular area (smart lockdowns) would not result in a complete shutdown of the whole cities.

14. Industrial Parks are essential facilities that should be built separately, and in case of pandemic lockdowns, they could continue to work in a bubble.

\section{ACKNOWLEDGMENT}

This research is supported by the Beijing Key Laboratory of Urban Spatial Information Engineering (NO. 20210218) and National Natural Science Foundation of China (No. 202202457).

\section{REFERENCES}

[1] Saidi, S., Mani, V., Mefteh, H., Shahbaz, M., \& Akhtar, P. (2020). Dynamic linkages between transport, logistics, foreign direct investment, and economic growth: empirical evidence from developing countries. Transportation Research Part A: Policy and Practice, 141, 277-293.

[2] Aschauer, D. A. (1989). Is public expenditure productive? Journal of Monetary Economics, 23(2), 177-200. https://doi.org/https://doi.org/10.1016/0304 3932(89)90047-0

[3] Lee, J. W. (2013). The contribution of foreign direct investment to clean energy use, carbon emissions and economic growth. Energy Policy, 55, 483-489.

[4] Beyzatlar, M. A., Karacal, M., \& Yetkiner, H (2014). Granger-causality between transportation and GDP: A panel data approach. Transportation Research Part A: Policy and Practice, 63, 43-55. https://doi.org/https://doi.org/10.1016/j.tra.2014.03.001

[5] Ramanathan, R. (2001). The long-run behaviour of transport performance in India: a cointegration approach. Transportation Research Part A: Policy and Practice, 35(4), 309-320. https://doi.org/https://doi.org/10.1016/S09658564(99)00060-9
[6] Shirley, C., \& Winston, C. (2004). Firm inventory behavior and the returns from highway infrastructure investments. Journal of Urban Economics, 55(2), 398 415.

https://doi.org/https://doi.org/10.1016/j.jue.2003.11.001

[7] Hong-wen, Z., Hong-yan, W., \& Yu-min, Z. (2007). The research of relationship between economic development and logistics development based on statistical analysis. 2007 International Conference on Management Science and Engineering, 1372-1377.

[8] WHO. (2021). WHO | Disease outbreaks by year. WHO. http://www.who.int/csr/don/archive/year/en/

[9] Solarin, S. A., \& Shahbaz, M. (2015). Natural gas consumption and economic growth: The role of foreign direct investment, capital formation and trade openness in Malaysia. Renewable and Sustainable Energy Reviews, 42, 835-845.

[10] Seidu, R. D., Young, B. E., Robinson, H., \& Michael, R. (2020). The impact of infrastructure investment on economic growth in the United Kingdom Journal of Infrastructure, Policy and Development, 4(2), 217-227.

[11] Can, B. E., Dinç, D. T., \& Gökmen, A. (2021). The Issue of Logistics and Its Correlation to Economic Growth in Turkey: An Empirical Application. International Journal of Applied Logistics (IJAL), 11(1), $66-80$.

[12] Hanif, S., Mu, D., Baig, S., \& Alam, K. M. (2020). A Correlative Analysis of Modern Logistics Industry to Developing Economy Using the VAR Model: A Case of Pakistan. Journal of Advanced Transportation, 2020.

[13] Tiba, S., \& Frikha, M. (2018). Income, trade openness and energy interactions: Evidence from simultaneous equation modeling. Energy, 147, 799-811. https://doi.org/https://doi.org/10.1016/j.energy.2018.01. 013

[14] Nasreen, S., \& Anwar, S. (2014). Foreign direct investment, growth and local financial markets: new evidence from Pakistan. International Journal of Economics and Business Research, 7(3), 336-348.

[15] Berechman, J., Ozmen, D., \& Ozbay, K. (2006). Empirical analysis of transportation investment and economic development at state, county and municipality levels. Transportation, 33(6), 537-551. https://doi.org/10.1007/s11116-006-7472-6 
[16] Talley, W. K., \& Ng, M. (2016). Port economic cost functions: A service perspective. Transportation Research Part E: Logistics and Transportation Review, $88,1-10$.

https://doi.org/https://doi.org/10.1016/j.tre.2015.12.002

[17] Khadaroo, A. J., \& Seetanah, B. (2010). Transport infrastructure and foreign direct investment. Journal of International Development: The Journal of the Development Studies Association, 22(1), 103-123.

[18] Lean, H. H., Huang, W., \& Hong, J. (2014). Logistics and economic development: Experience from China. Transport Policy, 32, 96-104.

[19] Chu, Z. (2012). Logistics and economic growth: a panel data approach. The Annals of Regional Science, 49(1), 87-102. https://doi.org/10.1007/s00168-0100434-0

[20] Gunasekera, K., Anderson, W., \& Lakshmanan, T. R. (2008). Highway-Induced Development: Evidence from Sri Lanka. World Development, 36(11), 23712389.

https://doi.org/https://doi.org/10.1016/j.worlddev.2007.1 0.014

[21] Wang, Q., \& Zhang, F. (2021). What does the China's economic recovery after the COVID-19 pandemic mean for the economic growth and energy consumption of other countries? Journal of Cleaner Production, 295, 126265.

[22] Olivia, S., Gibson, J., \& Nasrudin, R. an. (2020). Indonesia in the Time of Covid-19. Bulletin of Indonesian Economic Studies, 56(2), 143-174. 